\title{
Evidence on the effect of position change on pressure ulcer among hospitalized adult patients in Ethiopia: systematic review and meta-analysis
}

Wondimeneh Shibabaw Shiferaw ${ }^{1}$, Yared Asmare Aynalem ${ }^{1}$, Tadesse Yirga Akalu ${ }^{2}$

Wondimeneh Shibabaw Shiferaw, BSc, MSc ${ }^{1} *$ *Corresponding author

Lecturer of Nursing, Department of Nursing, College of Health Science, Debre Berhan University

Address: P.O. Box 445, Debre Berhan, Ethiopia

Email: wshibabaw2015@gmail.com

Yared Asmare Aynalem, BSc, MSc ${ }^{1}$

Lecturer of Nursing, Department of Nursing, College of Health Science, Debre Berhan University

Address: P.O. Box 445, Debre Berhan, Ethiopia

Email: yaredasmare123@gmail.com

Tadesse Yirga Akalu, BSc, MSc ${ }^{2}$

Lecturer of Nursing, Department of Nursing, College of Health Science, Debre markos University

Address: P.O. Box 269, Debre Markos, Ethiopia

Email: tadesseyirga680@gmail.com 


\begin{abstract}
Background: Pressure ulcers (PU) affect millions of people worldwide and always occur over bony areas of the body where pressure and tissue distortion is greatest. The national pooled prevalence of pressure ulcer remains unknown. Hence, this meta-analysis aimed to determine the effect of position change on pressure ulcer among hospitalized clients in Ethiopia.

Methods: Studies were retrieved through search engines in PubMed, Scopus, WHO afro library, Google Scholar, Africa journal online, PsycINFO and web-science following the Preferred Reporting Items for Systematic Review and Meta-Analysis Protocols (PRISMA-P). Analysis was done using STATA version 14 software. Heterogeneity between-study was checked using the $\mathrm{I}^{2}$ and examined a potential publication bias by visual inspection of the funnel plot and Egger's regression test statistic. The random-effect model was fitted to estimate the summary effects, odds ratios (ORs), and 95\% confidence interval (CIs) across studies.
\end{abstract}

Results: Out of the reviewing 401 studies, 7 studies fulfilled the inclusion criteria and were included in the meta-analysis. The estimated pooled prevalence of pressure ulcer in Ethiopia was $11.7 \%$ (95\% CI $(7.28,16.13 \%))$. Based on the subgroup analysis, the estimated magnitude of pressure ulcer was $15.89 \%$ (95\% CI: 35.34, 54.04) among studies their sample size were greater than or equals to 250 . Those clients who have position change during hospitalization were $82 \%$ less likely to develop pressure ulcer [(OR: $0.18(95 \% \mathrm{CI}(0.07,0.46))$ than their counter part.

Conclusion: The overall prevalence of pressure ulcer in Ethiopia was relatively high. Position change of the client during hospitalization had paramount benefit to reduce the burden of pressure ulcer. Therefore, policymakers (federal minister of health) could give special attention to minimize the magnitude of pressure ulcer, and to improve the overall quality of healthcare service. Further, meta-analysis study could be conducted to identify individual and health care service related factors to the occurrence of pressure ulcer.

Key words: pressure ulcer, pressure injury, decubitus ulcer, position change, Ethiopia. 


\section{Background}

Pressure ulcers (PU) affect millions of people worldwide and nearly always occur over bony areas of the body where pressure and tissue distortion is greatest. Pressure ulcer has variation in size and severity of damages to the skin, underlying tissue, muscle and over a bony prominence[1, 2]. Globally, recognized as one of the five most causes of harm to clients[3]. Though pressure injury is largely preventable patient safety problem, which have a major impact on the health care system and a trivial problem to patients, relatives and caregivers[4].Likewise, pressure ulcers highly threatens the well-being of clients by increased mortality rates, decrease quality of life, longer hospital stay and increase costs for patient care[5, 6].Moreover, pressure ulcer has detrimental impact on pain/suffering, disturbance of body image, delayed healing and have a negative effect on patients' overall performance[4, 7].

In addition to its impact on individual and heath care system, pressure ulcers carry a significant economic burden. Pressure ulcer is considered more expensive to treat than to prevent pressure ulcers [8]. It has been estimated that the cost of treating pressure ulcer is 2.5 times higher than the cost of preventing [9]. The total annual cost for treatment of PUs in the United Kingdom being (\$1.4-2.1 billion), making up 4\% of the annual national health service budget[10].

A meta-analysis study revealed that the overall global prevalence of PUs using point prevalence was $14.8 \%$ [11]. Likewise, a systematic review carried out in acute care settings showed between $6 \%$ and $18.5 \%[12]$. Other, meta-analysis report on the incidence of PU in the emergency department was $6.31 \%[13]$. Knowing the prevalence rates of PUs are serve as basic tools to identify the severity of problem, to design preventive strategies and for efficient use of healthcare resources[14]. In addition, it would be baseline data for quality indicators to measure health care delivery within the clinical settings [15].

Numerous studies have shown substantial variation on the prevalence of pressure ulcers among hospitalized patients across the globe and revealed that the prevalence pressure ulcer was $14.9 \%$ in Swedish [16] ,18.2\% in Norwegian [17],10.1\% in São Paulo [18], 1.58\% in China [19],3.3\% in Turkish Hospital [20], $18.7 \%$ in Brazil [21], 17.23\% in Sub-Saharan Tertiary Centre [22], $3.22 \%$ in South-west Nigeria [23], and $19.3 \%$ in Tunisia [24]. 
The existence of PUs is a very complex phenomenon and due to the presence of multiple risk factors [25]. Mainly, contributing factors are associated to the patient's condition, health care provider and health care delivery system [26]. A review of several studies, aimed to identify factors related to the pressure ulcer in clinical setting, indicated that immobility [5, 16, 27-29], length of hospital stay [16, 27, 29-32], Older age [16, 27, 33],reduced sensory perception [16, 30, 33, 34], fecal and urinary incontinence [33, 35], worse Braden scores[6, 27, 33, 36-38], comorbidity[6, 27], and nutrition[28, 34, 37, 39, 40] was found to be statically significant risk factor for PU. However, repositioning would reduce the magnitude of pressure over vulnerable areas of the body [1].

Identification of associated factors is the primary goal to decrease the incidence of PUs [41].Hence, determining risk factors used as benchmarks to design appropriate prevention measure, to improve client safety and efficient utilization of resources [42]. Moreover, preventive measures are generally divided into four main areas: assessment of pressure ulcer development risk, skin care and initial treatment, use of pressure-reducing support surfaces and education [43].Therefore, early detection of patients who are susceptible to pressure ulcer is crucial, and it is recommended that the first skin assessment should be performed within 8 hours of hospital admission[44].

Although the attention on PU prevention has low in Ethiopia. A pressure ulcer remains pressing problem and is a major issue in nursing care. Prevention of pressure ulcers is the key role of the nurse and it is one of the quality indicator of nursing care[43]. Despite, extensive data on developed country, there is no comprehensive PU prevalence report that would serve as baseline information to improve patient safety and provide quality nursing care. Therefore, the present meta-analysis is aimed to assess the effect of position change on pressure ulcer among adult hospitalized clients in Ethiopia. Finding from the current study would serve as benchmark for policy-makers to implement appropriate preventive measure and to alleviate the pressing problem of pressure ulcer. In addition, for clinicians estimating magnitude of pressure ulcer would reflect overall quality indicator for facilities and a way to assess the efficiency of prevention strategies. Furthermore, the results of this study could serve as an input for further PU studies in Ethiopia. 


\section{Methods}

\section{Design and search strategy}

This systematic review and meta-analysis was carried out by using the Preferred Reporting Items for Systematic Reviews and Meta-Analyses (PRISMA) Guidelines [45]. The search strategy was developed using Population Exposure Controls and Outcome (PECO) searching guide. A twostep search strategy was used to identify all relevant literature. First, seven electronic databases were systematically searched, such as MEDLINE (via PubMed), Google Scholar, Africa journal of online, Scopus, Web-science, WHO afro library, and PsycINFO to identify relevant studies electronically.Second, a hand search of gray literature and other related articles in order to identify additional relevant research, which may use as input in our meta-analysis and the reference lists of all retrieved articles was carried out to identify additional studies. In addition, all electronic sources of information were searched the study which is done from $1^{\text {st }}$ January/ 2000 to $1^{\text {st }}$ June, / 2019. The search was conducted using the following MeSH and free-text terms : "pressure ulcer", "pressure injury", “decubitus ulcer", "bed sore”, "position change" and "Ethiopia". Finally a completed PRISMA checklist has been included (Additional file 1: Table S1).

\section{PECO guide}

\section{Population}

All adult clients admitted to healthcare settings with age greater than 18 years old.

\section{Exposure}

The presence of position change of the client during hospital stay.

\section{Comparison}

Absence of position change of the client during hospital stay

\section{Outcome}

Pressure ulcer.

\section{Inclusion criteria}

Those articles which are conducted only in Ethiopia were included. Studies were eligible for inclusion in the review if they reported their outcome variable as prevalence of pressure ulcer. Likewise, we include studies conducted on person's ages greater than 18 in all healthcare 
settings and having a quantitative research design. Similarly, articles published in peer reviewed journals and gray literature reported in the English language until $1^{\text {st }}$ June $/ 2019$ were also included. Furthermore, we imposed restriction on date of publication in our literature search which is from $1^{\text {st }}$ January/ 2000 to $1^{\text {st }}$ June, / 2019.

\section{Exclusion criteria}

Those articles which didn't fully accessed at the time of our search process were excluded. Patients admitted with pressure ulcer. If we unable to assess the quality of each article in the absence of their full texts. Likewise, articles in which outcomes are not well defined were also excluded. Studies with poor quality as per stated criteria were also excluded from the review. Finally two authors (W.S. and Y.A.) independently evaluated the eligibility of all retrieved studies, and any disagreement and inconsistencies were resolved by discussion and consensus with the third author (T.Y.).

\section{Outcome measurement}

This review has considered studies that include all stages of pressure ulcer or equivalent as the outcome measure. Pressure ulcer is defined as a lesion of skin or underlying tissues by direct unrelieved pressure on the skin. Similarly, according to the National Pressure Ulcer Advisory Panel (NPUAP) has defined prevalence as "a cross-sectional count of the number of cases at a specific point in time, or the number of people with pressure ulcers who exist in a patient population at a given point in time"[46].

\section{Data extraction}

Data were extracted by three authors using a pre-piloted and standardized data extraction format prepared in a Microsoft excel. The data extraction sheet was piloted on 5 randomly selected papers and modified accordingly. This form was include the study characteristics, like author/s name, year of publication, study health institution, study design, sample size, prevalence, and the quality score of each study were extracted from each included article by three independent authors. Any disagreements at the time of data abstraction were reconciled by discussion and consensus. 


\section{Quality assessment}

The qualities of each studies were assessed using a standardized tool helps to classify risk of bias which can help to explain variation in the results of included studies. Methodological and other quality of each article was assessed by both authors based on a modified version of the Newcastle-Ottawa scale for cross-sectional study [47], a validated tool for assessing risk of bias in observational studies. After reviewing different literatures, we declared that articles scored $\geq 6$ points out of 10 points modified NOS components were considered to be high-quality: selection (5 points score), comparability (2 point score), and outcome assessment (3 point score). Furthermore, quality assurance check was independently performed by three authors.

Additional file 2: Table S1. Methodological quality assessment of cross-sectional studies using modified Newcastle - Ottawa Scale (NOS).

\section{Statistical analysis}

Data were abstracted by using Microsoft Excel sheet, then further analysis was done using STATA version 14 statistical software[48]. Results of the meta-analysis were reported as pooled prevalence of pressure injuries with $95 \%$ confidence intervals (CIs), p-values <0.05 were considered statistically significant. Heterogeneity across the studies were evaluated using the $\mathrm{I}^{2}$ statistics $(0 \% \sim 100 \%)$ [49]. $\mathrm{I}^{2}$ statistic with a value above $75 \%$ was interpreted as representing high heterogeneity. The analysis was done using the random effects model to calculate pooled effect estimates [50]. To minimize the random variations between the point estimates of the primary study, subgroup analysis was done based on study sample size. In addition, to identify the possible sources of heterogeneity, meta-regression was deployed by considering the year of publication and sample size as covariate[51]. The funnel plot graphically checked the existence of publication bias in meta-analyses. In addition, egger regression test was reported with a $\mathrm{p}<0.05$ being considered statistically significant, in order to avoid limitations of the funnel plot $[52,53]$. Moreover, we performed a sensitivity analysis to describe whether the pooled effect size was influenced by individual studies[54]. 


\section{Result}

\section{Search results}

We found that a total of 401 articles based on systematically international database search, of these, 392 studies were found from seven international databases and the remaining 9 were manual search. Databases includes, PubMed (4), Scopus (32), PsyInfo (13), Google scholar (246), WHO afro library (10), Web-science (79), and Africa online journal (8). Out of them, 226 duplicate records were recognised and removed. From the remaining 175 articles, 150 articles were excluded after reading of titles and abstracts based on the pre-defined inclusion criteria's. Finally, 25 full text articles were assessed for eligibility criteria. Based on the pre-defined criteria and quality assessment, only 7 articles were included for the final analysis (figure 1).

\section{Study baseline characteristics}

A total of 7 studies with 1,881 participants were included in this meta-analysis. Among 7 studies three were conducted in Amharic region [30, 40, 55], whereas the remaining was conducted in (SNNP [56], Harari [57] and Oromia [38]). Concerning, sample size most, (71.4\%) of the studies, their sample size were less than 250. Based on modified Newcastle Ottawa quality score assessment almost all seven article fulfil the required quality which is 7 and above. Moreover, all studies were also a cross-sectional that was conducted among clients admitted in different clinical setting of Ethiopia. 
Table 1. Baseline characteristics of studies included in the meta-analysis of pressure ulcer in Ethiopia.

\begin{tabular}{|c|c|c|c|c|c|c|c|}
\hline First Author & $\begin{array}{l}\text { Pub. } \\
\text { Year }\end{array}$ & Region & $\begin{array}{l}\text { Health Facility } \\
\text { Name }\end{array}$ & $\begin{array}{l}\text { Study } \\
\text { Design }\end{array}$ & $\begin{array}{l}\text { Sample } \\
\text { Size }\end{array}$ & $\begin{array}{l}\text { Prevalence } \\
\%(95 \% \mathrm{CI})\end{array}$ & $\begin{array}{l}\text { Quali } \\
\text { ty } \\
\text { score }\end{array}$ \\
\hline Benalfew. L etal[40] & 2016 & Amhara & $\begin{array}{l}\text { Debre markos } \\
\text { referral hospital }\end{array}$ & $\begin{array}{l}\text { Cross- } \\
\text { sectional }\end{array}$ & 236 & $3.4(1.08-5.71)$ & 7 \\
\hline Belachew .T etal[56] & 2015 & SNNP & $\begin{array}{ll}\text { Wolaita Sodo } \\
\text { University } \\
\text { Teaching } \\
\text { Hospital }\end{array}$ & $\begin{array}{l}\text { Cross- } \\
\text { sectional }\end{array}$ & 239 & $13.4(9.08-17.7)$ & 7 \\
\hline Feven .T etal[57] & 2016 & Harari & $\begin{array}{ll}\text { Hiwot Fana } \\
\text { haromiya } \\
\text { University } \\
\text { Hospital }\end{array}$ & $\begin{array}{l}\text { Cross- } \\
\text { sectional }\end{array}$ & 235 & $16.3(11.5-21.02)$ & 8 \\
\hline $\begin{array}{l}\text { Bereded,D.T } \\
\text { etal[55] }\end{array}$ & 2016 & Amhara & $\begin{array}{l}\text { Dessie Referral } \\
\text { Hospital }\end{array}$ & $\begin{array}{l}\text { Cross- } \\
\text { sectional }\end{array}$ & 355 & $14.9(11.2-18.6)$ & 8 \\
\hline Gedamu,H etal[30] & 2014 & Amhara & $\begin{array}{l}\text { Felegehiwot } \\
\text { referral hospital }\end{array}$ & $\begin{array}{l}\text { Cross- } \\
\text { sectional }\end{array}$ & 422 & $16.8(13.2-20.3)$ & 6 \\
\hline Ebrahim,J etal[34] & 2016 & SNNP & $\begin{array}{l}\text { Hawassa } \\
\text { University } \\
\text { Referral Hospital }\end{array}$ & $\begin{array}{l}\text { Cross- } \\
\text { sectional }\end{array}$ & 228 & $8.3(4.7-11.8)$ & 7 \\
\hline Assefa, T etal [38] & 2017 & Oromia & $\begin{array}{l}\text { Jimma University } \\
\text { Medical Center }\end{array}$ & $\begin{array}{l}\text { Cross- } \\
\text { sectional }\end{array}$ & 166 & $9.6(5.1-14.08)$ & 7 \\
\hline
\end{tabular}




\section{Prevalence of pressure ulcer in Ethiopia}

According to the present meta-analysis evidence the pooled prevalence of pressure ulcer in Ethiopia was $11.7 \%$ (95\% CI: 7.18-16.13) (Figure 2). Using random effects model statistically significant level of heterogeneity was observed $\left(\mathrm{I}^{2}=90.3 \%\right.$; $\left.<<0.001\right)$. The presence of significant heterogeneity among the primary studies requires the need to conduct subgroup analysis. As a result, in order to identifying the sources of heterogeneity we had deployed sub group analysis by using study sample size to determine the pooled prevalence of pressure ulcer (Figure 3). The finding of subgroup analysis, showed that, the highest burden of pressure ulcer were observed among studies groups whose sample size was greater than or equals to 250 which is $15.89 \%$ (95\% CI: $\left.13.32,18.46), \mathrm{I}^{2}=0.0 \%\right)$.

\begin{tabular}{|c|c|c|c|}
\hline Author year & & Prevalence $(95 \% \mathrm{Cl})$ & $\begin{array}{l}\% \\
\text { Weight }\end{array}$ \\
\hline Benalfew L etal (2016) & $\longrightarrow$ & $3.40(1.09,5.71)$ & 15.35 \\
\hline Belachew T etal (2015) & $\therefore$ & $13.40(9.08,17.72)$ & 13.90 \\
\hline Feven T etal (2016) & 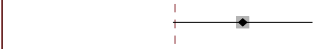 & $16.30(11.58,21.02)$ & 13.55 \\
\hline Bereded, D.T etal (2016) & - & $14.90(11.20,18.60)$ & 14.41 \\
\hline Gedamu, $H$ etal (2014) & - & $16.80(13.23,20.37)$ & 14.51 \\
\hline Ebrahim, J etal (2016) & & $8.30(4.72,11.88)$ & 14.50 \\
\hline Assefa, T etal (2017) & - & $9.60(5.12,14.08)$ & 13.76 \\
\hline Overall (I-squared $=90.3 \%, p<0.001)$ & & $11.70(7.28,16.13)$ & 100.00 \\
\hline NOTE: Weights are from random effects analysis & & & \\
\hline
\end{tabular}

Figure 2. Forest plot showing the pooled prevalence of pressure ulcer in Ethiopia 


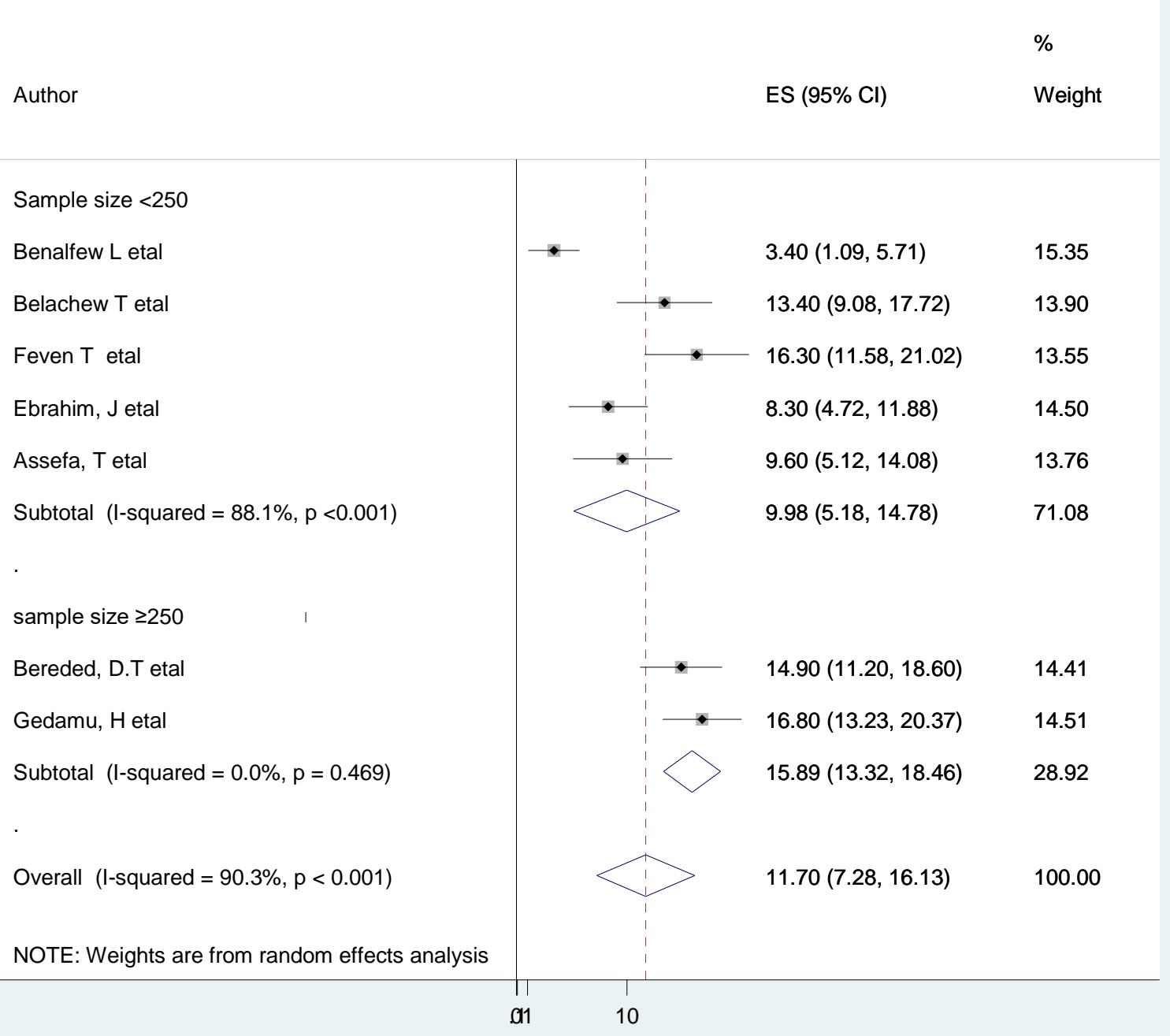

Figure 3. Subgroup analysis by sample size on the pooled prevalence of pressure ulcer.

\section{Meta-regression analysis}

As the test statistic shows that there were a significant heterogeneity within and between the included studies $\left(\mathrm{I}^{2}\right.$ statistics $\left.=90.3 \%\right)$. Hence, in order to minimize the source of heterogeneity between the point estimates of the primary study, subgroup analysis was done based on study sample size. In addition, in order to identify the possible source of heterogeneity, we have performed meta-regression by using publication year and sample size as continuous variable of each articles as covariate of interest. Moreover, the result of the meta-regression analysis 
revealed that publication year and sample size were not statistically significant for the presence of heterogeneity (Table 2).

Table 2. Meta regression analysis for the included studies to identify source of heterogeneity

\begin{tabular}{|l|l|l|l|l|l|}
\hline Variable & Coef. & Std. err. & $\mathrm{t}$-value & $\mathrm{P}>|\mathrm{t}|$ & $95 \%$ Conf. Interval \\
\hline Publication year & -0.0058338 & 1.328554 & -0.00 & 0.997 & $(-3.69,3.680)$ \\
\hline Total sample size & 0.0003882 & 0.0140162 & 0.03 & 0.979 & $(-0.038,0.039)$ \\
\hline
\end{tabular}

\section{Publication bias}

To identify the presence or absence of publication bias funnel plot, egger's regression test was performed. In this meta-analysis funnel plots indicated evidence of publication bias. Each point in funnel plots represents a separate study and asymmetrical distribution is evidence of the existence of publication bias and visual inspection of the funnel plot also suggests asymmetry distribution (Figure 4). Likewise, the result of Egger's test was statistically significant for the presence of publication bias $(\mathrm{P}=0.036)$. In addition, to reducing and adjusting publication bias trim and fill analysis was also performed (Figure 5). Trim and fill analysis is a nonparametric methods for estimating the number of missing studies that might exist.

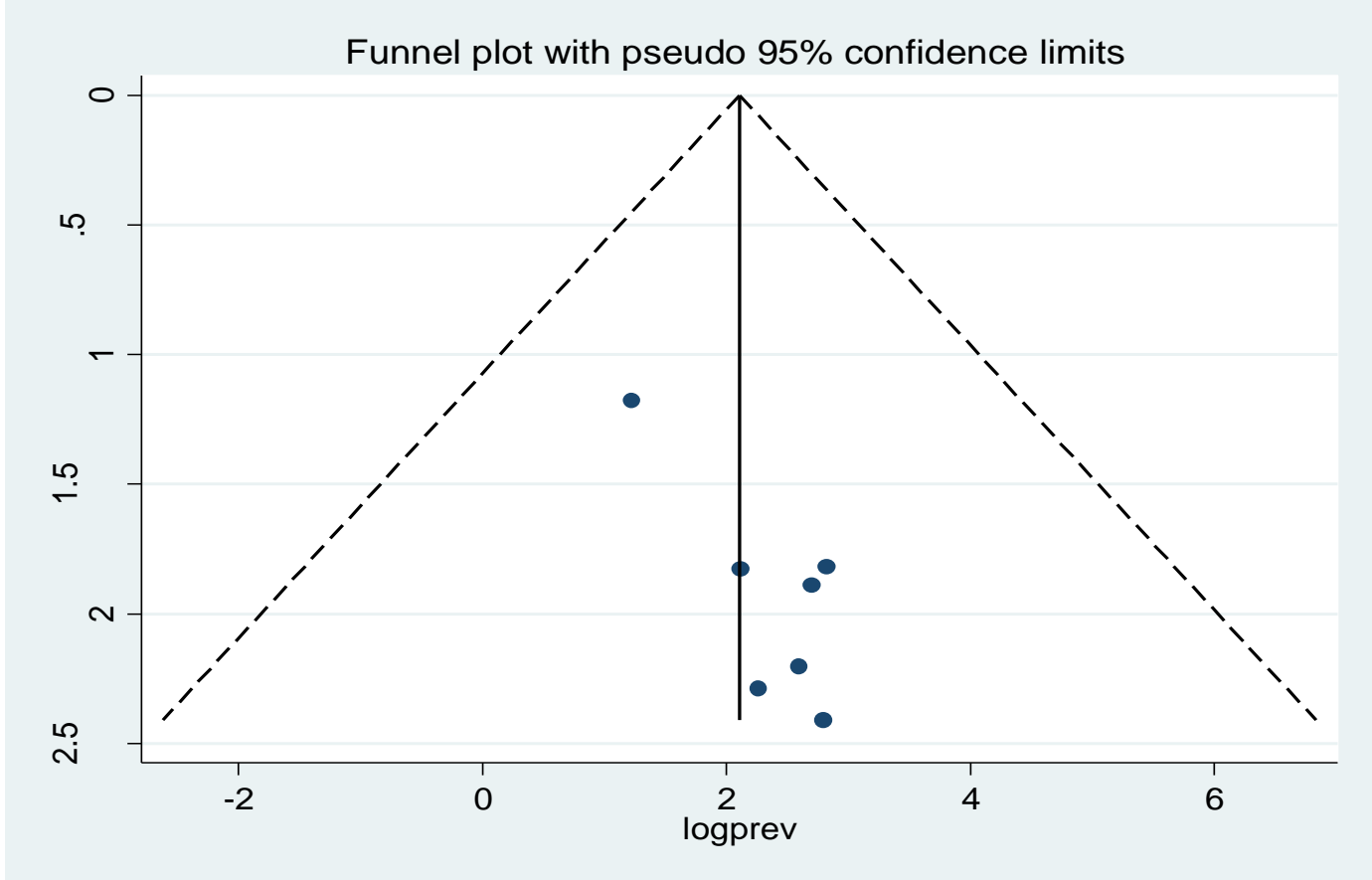


Figure 4: Funnel plot to test publication bias of the 7 studies

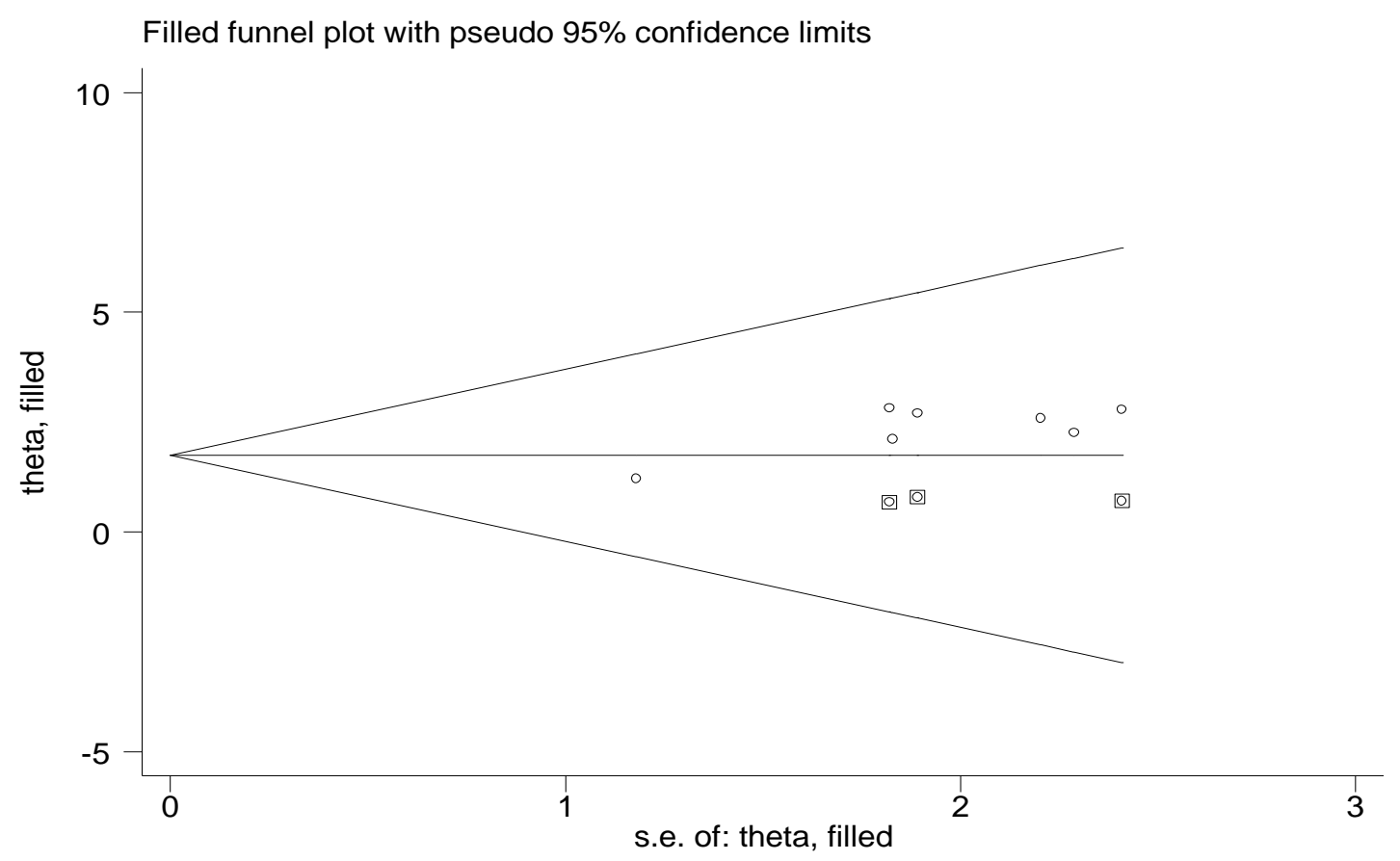

Figure 5.Result of trim and filled analysis for adjusting publication bias of the 7 studies.

\section{Sensitivity analysis}

The finding of sensitivity analyses using random effects model revealed that no single study affected the overall magnitude of pressure ulcer (figure 6). 


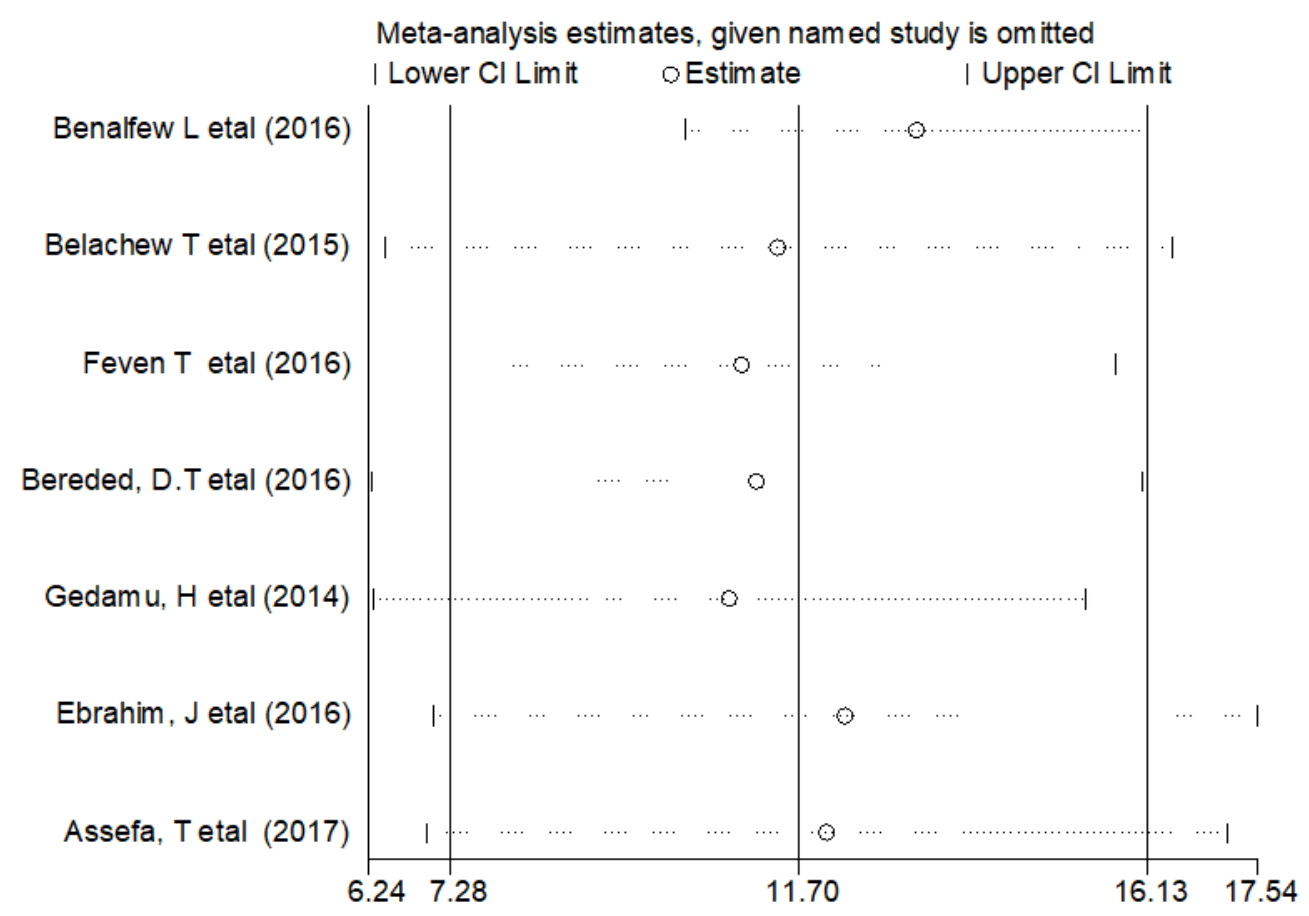

Figure 6: Result of sensitivity analysis of the 7 studies

\section{The association between position change and pressure ulcer}

The finding of the current meta-analysis revealed that, those clients who were changed their position by nurses had $82 \%$ less chance of developing pressure ulcer compared with those who have no position change during hospitalization (OR: 0.18 (95\% CI $(0.07,0.46)$ ) (Figure 7). The heterogeneity test $\left(\mathrm{I}^{2}=85 \%, \mathrm{P}<0.001\right)$ shows significant evidence of variation across studies. However, the evidence from Egger's test shows that no significant proof of publication bias $(\mathrm{P}=$ $0.180)$. 


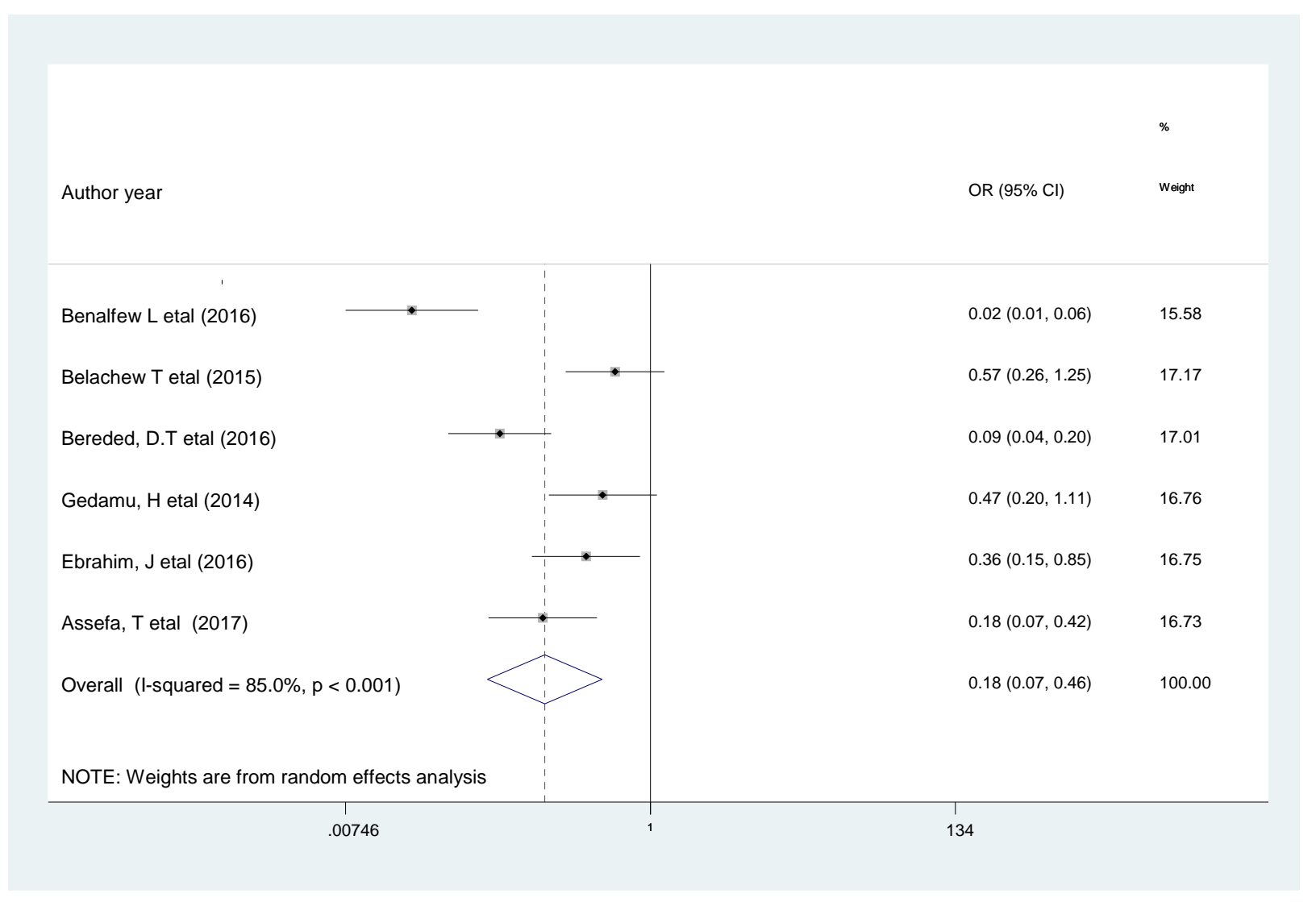

Figure 7: Forest plot showing the association between position change and pressure ulcer in Ethiopia

\section{Discussion}

The main aim of the current meta-analysis is to provide up-to-date knowledge on effect of position change on pressure ulcer in Ethiopia. In line with the objective, the present findings revealed that the pooled prevalence of pressure ulcer in Ethiopia was $11.7 \%$ (95\% CI: 7.28, $16.13 \%$ ). The result of the current meta-analysis is in line with other meta-analysis study done on the global prevalence of pressure ulcer $14.8 \%$ [11], a systematic review carried out in acute care settings between 6\% and 18.5\%[12], 14.9\% in Swedish [16] and 10.1\% in São Paulo [18]. On the other hand, our finding is higher than a study done in China 1.58\% [19],3.3\% in Turkish Hospital [20], and 3.22\% in South-west Nigeria [23]. In contrary, the current study is low than $17.23 \%$ in Sub-Saharan Tertiary Centre [22], 18.2\% in Norwegian [17], $18.7 \%$ in Brazil [21], and $19.3 \%$ in Tunisia [24]. The possible explanations for the above variations might be methodological differences (i.e., data analysis and eligibility of study participants), variation in 
quality of care and educational preparation among health care provider, policy and strategy difference. Other plausible reasons for the observed difference between the pooled estimates could be variation in sampling, and the tool used for assessing the pressure injuries.

In the current meta-analysis, we had performed sub-group analysis based on the study sample size (i.e. sample size $<250$ and $\geq 250$ ) in which the studies were conducted. As a result, the findings of the subgroup analysis revealed that variability was observed in the overall pooled prevalence across the category of each sample size. Among the category of sample size the highest pooled prevalence of pressure ulcer was observed from those studies their sample size were greater than or equal to 250 which revealed that $15.89 \%(95 \% \mathrm{CI}$ : $13.32,18.46)$.In addition the observed high heterogeneity was explored by publication year and sample size using a metaregression analysis, although the results did not show any statistical significance. The possible explanation for this variation might be if the sample size is increase would provide the true estimate of the effect.

The current meta-analysis was also determined the association between client position change and pressure ulcer. Those who had position change during hospitalization was reduced the chance of pressure ulcer by $82 \%$ than those who had not implement position change during hospital stay. This finding is in line with the report in revised national pressure ulcer advisory panel [1] and other different study which is conducted across the globe \{32-34].This work is depending on previous research, through adapted methods, a comprehensive search of the literature, and strict eligibility criteria applied. We also carry out quality assessment, with consideration of study attrition, participation and confounding factors as a means of highlighting study bias and limitations.

The current study has implications for clinical practice. The finding would serve as base line for health care provider to establishing robust preventive measures for averting pressure ulcer. The finding serves as alarming the nursing education institution to facilitate and encourage about the prevention strategy of pressure ulcer, and giving a focus on the application of standardized care. Health care setting should be adequately staffed with nurses to prevent pressure ulcer and to implement client reposition during their hospitalization. Furthermore, design different strategies 
and training could be deployed to enhance the implementation of client reposition and to minimize the burden of pressure ulcer as a standardize plan of care.

Even though, there were some limitations, the present meta- analysis has provided important information and synthesis evidence regarding the effect of position change on pressure ulcer; first limitation is, the present study was include only English articles were considered to conduct this nationally based review. Second, it was challenging to synthesis some additional factors meanwhile they were not examined in a related approach across the studies. Third, many of the included studies did not report baseline sociodemographic characteristics of the participants. This prevented a subgroup analyses to estimate the prevalence of pressure ulcer using each variable. Furthermore, all included studies reported hospital-based populations and so this review does not consider home-dwelling people with pressure ulcer. Finally, almost all included studies were cross-sectional which might weaken the strength of evidence and hinder causality inference.

\section{Conclusion}

The overall pooled prevalence of pressure ulcer in Ethiopia was relatively high. Position change of the client during hospitalization had paramount benefit to reduce the burden of pressure ulcer. Therefore, policymakers could give special attention to minimize the magnitude of pressure ulcer in order to improve the overall quality of healthcare service. Further, meta-analysis study will be needed to identify individual and health care service related factors to the occurrence of pressure ulcer. Providing this information will inform effective strategies for preventing pressure ulcer in future.

\section{Abbreviations}

CI: Confidence Interval, OR: Odds Ratio, PRISMA: Preferred Reporting Items for Systematic Reviews and Meta-Analyses, SNNP: Southern Nations, Nationalities, and Peoples.

\section{Declarations}

\section{Ethics approval and consent to participate}

Not applicable.

\section{Consent for publication}

Not applicable. 


\section{Availability of data and materials}

The data analyzed during the current meta-analysis is available from the corresponding author on reasonable request.

Competing interests

The authors declare that they have no competing interests.

\section{Funding}

Not applicable.

\section{Authors' contributions}

WSS and TYA developed the protocol and involved in the design, selection of study, data extraction, and statistical analysis and developing the initial drafts of the manuscript. YAA, and TYA involved in data extraction, quality assessment, statistical analysis and revising. WSS and YAA prepared the final draft of the manuscript. All authors read and approved the final draft of the manuscript.

\section{Acknowledgements}

We would like to thank all authors of studies included in this meta-analysis.

\section{Reference}

1. Edsberg LE, Black JM, Goldberg M, McNichol L, Moore L, Sieggreen M: Revised National Pressure Ulcer Advisory Panel pressure injury staging system: revised pressure injury staging system. Journal of Wound, Ostomy, and Continence Nursing 2016, 43(6):585.

2. Haesler E: National pressure ulcer advisory panel, european pressure ulcer advisory panel and pan pacific pressure injury alliance. Prevention and treatment of pressure ulcers: quick reference guide[Internet] 2014.

3. etal. RM: Australian council on healthcare standards. Primary Intention. 2005, 13: 104-117.

4. Gorecki C, Brown JM, Nelson EA, Briggs M, Schoonhoven L, Dealey C, Defloor T, Nixon J, group EQoLPUP: Impact of pressure ulcers on quality of life in older patients: a systematic review. Journal of the American Geriatrics Society 2009, 57(7):1175-1183.

5. Kuptniratsaikul V, Kovindha A, Suethanapornkul S, Manimmanakorn N, Archongka Y: Complications during the rehabilitation period in Thai patients with stroke: a 
multicenter prospective study. American journal of physical medicine \& rehabilitation 2009, 88(2):92-99.

6. Capon A, Pavoni N, Mastromattei A, Di Lallo D: Pressure ulcer risk in long-term units: prevalence and associated factors. Journal of advanced nursing 2007, 58(3):263272.

7. Moore Z, Price P: Nurses' attitudes, behaviours and perceived barriers towards pressure ulcer prevention. Journal of clinical nursing 2004, 13(8):942-951.

8. Spetz J, Brown DS, Aydin C, Donaldson N: The value of reducing hospital-acquired pressure ulcer prevalence: an illustrative analysis. Journal of Nursing Administration 2013, 43(4):235-241.

9. Oot-Giromini B, Bidwell FC, Heller NB, Parks ML, Prebish EM, Wicks P, Williams PM: Pressure ulcer prevention versus treatment, comparative product cost study. Advances in Skin \& Wound Care 1989, 2(3):52-55.

10. Bennett G, Dealey C, Posnett J: The cost of pressure ulcers in the UK. Age and ageing 2004, 33(3):230-235.

11. Al Mutairi KB, Hendrie D: Global incidence and prevalence of pressure injuries in public hospitals: A systematic review. Wound Medicine 2018, 22:23-31.

12. Tubaishat A, Papanikolaou P, Anthony D, Habiballah L: Pressure ulcers prevalence in the acute care setting: a systematic review, 2000-2015. Clinical nursing research 2018, 27(6):643-659.

13. Liu P, Shen W-Q, Chen H-L: The Incidence of Pressure Ulcers in the Emergency Department: A Metaanalysis. In.; 2017.

14. Baharestani MM, Black JM, Carville K, Clark M, Cuddigan JE, Dealey C, Defloor T, Harding KG, Lahmann NA, Lubbers MJ: Dilemmas in measuring and using pressure ulcer prevalence and incidence: an international consensus. International wound journal 2009, 6(2):97-104.

15. Nguyen K-H, Chaboyer W, Whitty JA: Pressure injury in Australian public hospitals: a cost-of-illness study. Australian Health Review 2015, 39(3):329-336.

16. Gunningberg L, Stotts NA, Idvall E: Hospital-acquired pressure ulcers in two Swedish County Councils: cross-sectional data as the foundation for future quality improvement. International wound journal 2011, 8(5):465-473.

17. Bredesen IM, Bjøro K, Gunningberg L, Hofoss D: The prevalence, prevention and multilevel variance of pressure ulcers in Norwegian hospitals: a cross-sectional study. International journal of nursing studies 2015, 52(1):149-156.

18. Melleiro MM, Tronchin DMR, Baptista CMC, Braga AT, Paulino A, Kurcgant P: Pressure ulcers prevalence indicators and patient falls incidence in teaching hospitals in the city of São Paulo. Revista da Escola de Enfermagem da USP 2015, 49(SPE2):55-59.

19. Jiang Q, Li X, Qu X, Liu Y, Zhang L, Su C, Guo X, Chen Y, Zhu Y, Jia J: The incidence, risk factors and characteristics of pressure ulcers in hospitalized patients in China. International journal of clinical and experimental pathology 2014, 7(5):2587.

20. Biçer E, Güçlüel Y, Türker M, Kepiçoglu N, Sekerci Y, Say A: Pressure Ulcer Prevalence, Incidence, Risk, Clinical Features, and Outcomes Among Patients in a Turkish Hospital: A Cross-sectional, Retrospective Study. Wound management \& prevention 2019, 65(2):20-28. 
21. Strazzieri-Pulido KC, S. González CV, Nogueira PC, Padilha KG, G. Santos VL: Pressure injuries in critical patients: Incidence, patient-associated factors, and nursing workload. Journal of nursing management 2019, 27(2):301-310.

22. Asiyanbi G, Adekola O, Desalu I: A Retrospective study of Pressure ulcers in critically ill patients in a Sub-Saharan Tertiary Centre. African Journal of Anaesthesia and Intensive Care 2014, 14(2).

23. Adegoke B, Odole A, Akindele L, Akinpelu A: Pressure ulcer prevalence among hospitalised adults in university hospitals in South-west Nigeria. Wound Practice \& Research: Journal of the Australian Wound Management Association 2013, 21(3):128.

24. Ghali H, Rejeb $\mathrm{B}$, Chelly $\mathrm{S}$, Cheikh $\mathrm{AB}$, Khefacha S, Latiri H: Incidence and risk factors of pressure ulcers in a Tunisian University Hospital. Revue d'Épidémiologie et de Santé Publique 2018, 66:S340.

25. Shahin ES, Dassen T, Halfens RJ: Incidence, prevention and treatment of pressure ulcers in intensive care patients: a longitudinal study. International journal of nursing studies 2009, 46(4):413-421.

26. Lindgren M, Unosson M, Fredrikson M, Ek AC: Immobility-a major risk factor for development of pressure ulcers among adult hospitalized patients: a prospective study. Scandinavian journal of caring sciences 2004, 18(1):57-64.

27. Børsting TE, Tvedt CR, Skogestad IJ, Granheim TI, Gay CL, Lerdal A: Prevalence of pressure ulcer and associated risk factors in middle-and older-aged medical inpatients in Norway. Journal of clinical nursing 2018, 27(3-4):e535-e543.

28. Suttipong C, Sindhu S: Predicting factors of pressure ulcers in older Thai stroke patients living in urban communities. Journal of clinical nursing 2012, 21(3-4):372379.

29. Sayar S, Turgut S, Doğan H, Ekici A, Yurtsever S, Demirkan F, Doruk N, Taşdelen B: Incidence of pressure ulcers in intensive care unit patients at risk according to the Waterlow scale and factors influencing the development of pressure ulcers. Journal of Clinical Nursing 2009, 18(5):765-774.

30. Gedamu H, Hailu M, Amano A: Prevalence and associated factors of pressure ulcer among hospitalized patients at Felegehiwot referral hospital, Bahir Dar, Ethiopia. Advances in Nursing 2014, 2014.

31. Pokorná A, Benešová K, Jarkovský Jí, Mužík J, Beeckman D: Pressure Injuries in Inpatient Care Facilities in the Czech Republic. Journal of Wound, Ostomy and Continence Nursing 2017, 44(4):331-335.

32. Zhao G, Hiltabidel E, Liu Y, Chen L, Liao Y: A cross-sectional descriptive study of pressure ulcer prevalence in a teaching hospital in China. Ostomy/wound management 2010, 56(2):38.

33. Shahin ES, Dassen T, Halfens RJ: Pressure ulcer prevalence in intensive care patients: a cross-sectional study. Journal of evaluation in clinical practice 2008, 14(4):563-568.

34. Ebrahim J, Deribe B, Biru W, Feleke T: Prevalence and Factors Associated with Pressure Ulcer among Patients Admitted in Hawassa University Referral Hospital, South Ethiopia. J Health Care Prev 2018, 1(105):2.

35. Beeckman D, Van Lancker A, Van Hecke A, Verhaeghe S: A systematic review and meta-analysis of incontinence-associated dermatitis, incontinence, and moisture as 
risk factors for pressure ulcer development. Research in nursing \& health 2014, 37(3):204-218.

36. Sving E, Idvall E, Högberg H, Gunningberg L: Factors contributing to evidence-based pressure ulcer prevention. A cross-sectional study. International journal of nursing studies 2014, 51(5):717-725.

37. Ben FM, Ben KJ, Khalfallah M, Jarraya D, Jarraya H, Ouahchi Z, Nouira R, Dziri C: Prevalence and risk factors of pressure ulcers in a Tunisian hospital. La Tunisie medicale 2017, 95(7):494-499.

38. Assefa T, Mamo F, Shiferaw D: Prevalence of Bed Sore and its associated Factors among Patients admitted at Jimma University Medical Center, Jimma Zone, Southwestern Ethiopia, 2017 Cross-sectional study. 2017.

39. Skogestad IJ, Martinsen L, Børsting TE, Granheim TI, Ludvigsen ES, Gay CL, Lerdal A: Supplementing the Braden scale for pressure ulcer risk among medical inpatients: the contribution of self-reported symptoms and standard laboratory tests. Journal of clinical nursing 2017, 26(1-2):202-214.

40. Mengisitie BL: Prevalence and Associated Factors of Pressure Ulcer among Hospitalized Adults at Debre Markos Referral Hospital, East Gojjam Zone, Ethiopia,2016. gray literature found from addis ababa university website 2016.

41. Lindgren M, Unosson M, Krantz AM, Ek AC: A risk assessment scale for the prediction of pressure sore development: reliability and validity. Journal of advanced nursing 2002, 38(2):190-199.

42. VanGilder C, MacFarlane GD, Meyer S: Results of nine international pressure ulcer prevalence surveys: 1989 to 2005. Ostomy Wound Management 2008, 54(2):40.

43. Pancorbo-Hidalgo PL, Garcia-Fernandez FP, Lopez-Medina IM, Alvarez-Nieto C: Risk assessment scales for pressure ulcer prevention: a systematic review. Journal of advanced nursing 2006, 54(1):94-110.

44. Hommel A, Santy-Tomlinson J: Pressure Injury Prevention and Wound Management. In: Fragility Fracture Nursing. edn.: Springer; 2018: 85-94.

45. Liberati A, Altman DG, Tetzlaff J, Mulrow C, Gøtzsche PC, Ioannidis JP, Clarke M, Devereaux PJ, Kleijnen J, Moher D: The PRISMA statement for reporting systematic reviews and meta-analyses of studies that evaluate health care interventions: explanation and elaboration. PLoS medicine 2009, 6(7):e1000100.

46. Black J, Baharestani MM, Cuddigan J, Dorner B, Edsberg L, Langemo D, Posthauer ME, Ratliff C, Taler G: National Pressure Ulcer Advisory Panel's updated pressure ulcer staging system. Advances in skin \& wound care 2007, 20(5):269-274.

47. Shea BJ, Reeves BC, Wells G, Thuku M, Hamel C, Moran J, Moher D, Tugwell P, Welch V, Kristjansson E: AMSTAR 2: a critical appraisal tool for systematic reviews that include randomised or non-randomised studies of healthcare interventions, or both. Bmj 2017, 358:j4008.

48. StataCorp L: Stata statistical software (version release 14). College Station, TX: Author 2015.

49. Borenstein M, Hedges LV, Higgins JP, Rothstein HR: Introduction to meta-analysis: John Wiley \& Sons; 2011.

50. Higgins JP, Thompson SG, Deeks JJ, Altman DG: Measuring inconsistency in metaanalyses. Bmj 2003, 327(7414):557-560. 
51. Begum F, Ghosh D, Tseng GC, Feingold E: Comprehensive literature review and statistical considerations for GWAS meta-analysis. Nucleic acids research 2012, 40(9):3777-3784.

52. Egger M, Davey-Smith G, Altman D: Systematic reviews in health care: meta-analysis in context: John Wiley \& Sons; 2008.

53. Rücker G, Schwarzer G, Carpenter J: Arcsine test for publication bias in metaanalyses with binary outcomes. Statistics in medicine 2008, 27(5):746-763.

54. Cummings $P$ : The relative merits of risk ratios and odds ratios. Archives of pediatrics \& adolescent medicine 2009, 163(5):438-445.

55. Bereded DT, Salih MH, Abebe AE: Prevalence and risk factors of pressure ulcer in hospitalized adult patients; a single center study from Ethiopia. BMC research notes 2018, 11(1):847.

56. Belachew T: Prevalence and Associated Factors of Pressure Ulcer among Adult Inpatients in Wolaita Sodo University Teaching Hospital, Southern Ethiopia. Prevalence 2016, 6(11).

57. Feven T: Magnitude and Factors Affecting the Development of Pressure Ulcer Among Bedridden Patients at Public Hospitals of Harari Regional State. Haramaya University; 2015. 